\title{
Presentation and Immediate Outcome of Surgical Treatment of Patients with Carcinoma of the Stomach - A Comparative Study between Young and Elderly patients
}

\author{
SA CHOWDHURY ${ }^{\mathrm{a}}$, MM HUSSAIN ${ }^{\mathrm{b}}$, J AHMED ${ }^{\mathrm{c}}$
}

Summary:

Carcinoma of the stomach is a common malignancy and have a high mortality. Incidence under the age of 45 is comparatively low but appear more aggressive then elderly group. This study was designed to describe the presentation and operative findings in the two groups of patients and to record the outcome of surgical management in these patients.

A total of 86 cases were included in this study. 14 were from below 40 years (young group) and 72 were above 40 years (elderly group). Young patients had less definitive symptoms than elderly group. Pain (85.71\%) and vomiting (78\%) were the most prominent symptoms in both the groups. But in elderly a significant number $54(75 \%)$ of cases had anorexia. Lump and visible peristalsis were present in both groups in approximately similar proportion. Histopathologically younger patients had more aggressive disease than the elderly group..

Introduction:

Carcinoma of the stomach is the second most common cancer worldwide. Higher incidence have been reported from Japan, China and South Korea and a lower incidence have been reported from India, Pakistan and Thiland ${ }^{1}$. Some series have reported overall 5 year survival rate of about $5 \%{ }^{2}$. Carcinoma of the stomach is rare under age 40 years, from which point the risk gradually increases with age. The mean age at diagnosis is 63 years ${ }^{3}$. It is about twice as common in men as in

a. Dr. Shafiul Azam Chowdhury FCPS, Resident Surgeon, Comilla Medical College

b. Professor Md Margub Hussain, Professor of Surgery, Dhaka Medical College

c. Dr. Jasimuddin Ahmed, Associate Professor of Surgery Chittagong Medical College

Address of Correspondance: Dr. Shafiul Azam Chowdhury FCPS, Resident Surgeon , Comilla Medical College

Received: 12 June, 2008

Accepted: 24 June, 2010
The operability in carcinoma of the stomach was more in young group probably due to physical fitness of patient. In both the groups antrum was the commonest site of malignancy. The incidence of malignancy in body was more in young patients. In young group tumor status was $T_{4}$ in $54.5 \%$ and in elderly group $56 \%$ was in $\mathrm{T}_{4}$ stage. $80 \%$ had lymph node involvement in both the groups. Resection was possible in young group in about $90 \%$ and gastrojejunostomy in $9.09 \%$ cases. Conversely, in the elderly group resection was possible in $58 \%$ and gastrojejunostomy was done in $42 \%$ cases. Total gastrectomy was done in $18.18 \%$ in young group and $4 \%$ in elderly group. Another important finding was partial gastrectomy was done in $72.73 \%$ in young but $46 \%$ in elderly only. The mortality was more (18.2\%) in young group in comparison to (10\%) in elderly.

Gastric carcinoma was found more aggressive in young with high mortality and morbidity. Efforts should be taken for early diagnosis and prompt surgical treatment.

(J Bangladesh Coll Phys Surg 2010; 28: 145-150)

women $^{3}$. Gastric cancer rarely disseminates widely before it involves the lymph nodes and therefore some believe this is an opportunity to cure the disease prior to dissemination ${ }^{2}$. It occurs in the younger individuals with a much higher rate of mortality and morbidity ${ }^{4}$. Early diagnosis is therefore the key to success in management of patients presenting with this disease. The only treatment modality to cure the disease is resectional surgery and chemotherapy ${ }^{2}$. In a study in Chittagong Medical College the incidence of carcinoma of the stomach in hospitalized patients was $6.96 \%{ }^{5}$. The risk factors of gastric carcinoma in Chittagong and its sea belt area was alcohol, dried and salted fish intake. Although the etiological factors and pathogenesis of gastric carcinoma are not yet fully understood ${ }^{6}$, the most important pathological determinant to evaluate clinical and prognostic significance is the depth of penetration of stomach wall by the lesion. The others 
are histological types, location of primary site and metastasis.

A study was conducted to compare the clinical presentation, operative findings and outcome of surgery between two age groups of patients presenting as carcinoma stomach.

\section{Materials and Method:}

This was a prospective quasi experimental study. The study was carried out in the Department of Surgery, Chittagong Medical College \& Hospital. The study was undertaken during the period of May 2002 to December 2003. Cases were selected consecutively following the inclusion and exclusion criteria. Evaluation of patients was based on history, physical examinations and investigations. For analysis of results patients were divided into two groups as Group A, below 40 years and Group B above 40 years of age .

a) Inclusion Criteria: Patient of either sex admitted with presentations suggestive of carcinoma of the stomach and histopathologically confirmed from tissue obtained by endoscopy.

b) Exclusion Criteria: Histopathologically negative cases were excluded.

Patients were admitted from surgical out-patient departments after clinical diagnosis of Carcinoma of the stomach. Some of these patients had tissue confirmation before being admitted. Referred patients from medical units after diagnosis of Carcinoma of the stomach were also included.

Preoperative clinical assessment included detailed history regarding presenting illness, dietary pattern and personal habits. Meticulous systematic physical examination was performed in each case. Ultrasonography was done to detect secondary deposits in liver, involvement of lymph nodes and presence of ascitis. Radioisotope scan of liver and bone was obtained in relevant cases. All relevant information were recorded methodically and carefully as far as possible in predesigned data sheet for each individual case.

During laparotomy tumor size, serosal involvement, hepatic metastasis, lymph node involvement including group, size and number, peritoneal metastasis and ascitis were observed and recorded in detail . Specimen was obtained in every operated case for histopathological reconfirmation.
Operability was judged on the basis of clinical and investigation findings. All had palliative surgery . The operative procedures included total gastrectomy, proximal or distal partial gastrectomy, subtotal gastrectomy and gastrojejunostomy along with removal of lymph nodes based on findings at laparotomy.

Post-operatively all patients were monitored carefully and complications were recorded. All the patients got $1^{\text {st }}$ cycle chemotherapy as per advice of Oncologist.

\section{Statistical analysis}

Statistical analysis was done manually and by using computer statistical software package SPSS-10.0 for windows 2000 (SPSS-Statistical Programme for Scientific Study). 'Unpaired t' tests were done where applicable. P values less than 0.05 was considered as significant, by setting the minimal level of statistical significance at 5\%.

\section{Ethical issues}

Permission for the study was duly obtained from Ethical Committee of Chittagong Medical College. On ethical consideration the patients were first explained about the treatment procedures with their possible outcome. Informed written consent was taken from them.

\section{Results:}

A total of 86 patients were included in the study. Only $14(16.3 \%)$ cases were below 40 years (Group A) and $72(83.7 \%)$ cases were above 40 years (Group B). The male: female ratio was 2.58:1

\section{Table-I}

\begin{tabular}{|c|c|c|}
\hline Symptoms & $\begin{array}{c}\text { Group A* } \\
n=14\end{array}$ & $\begin{array}{c}\text { Group B } \\
n=72\end{array}$ \\
\hline Dyspepsia & 02(14.28) & $34(47.22)$ \\
\hline in in the abdomen & $12(85.71 \%)$ & $52(72.22)$ \\
\hline omiting & $11(78 \%)$ & $54(75)$ \\
\hline [emetemesis and Melena & 00 & $05(6.94)$ \\
\hline ump in the abdomen & 06(42.85\%) & $18(25)$ \\
\hline Anorexia & 07 (50\%) & $54(75)$ \\
\hline Gen. weakness & $07(50 \%)$ & $43(59.72)$ \\
\hline \multicolumn{3}{|l|}{ Personal habits } \\
\hline Smoking & $6(43 \%)$ & $41(57 \%)$ \\
\hline Smoked and Salted fish & $7(50 \%)$ & $26(36 \%)$ \\
\hline
\end{tabular}

- Figures in parentheses represent percentages 
In Group A, 12 (85.7\%) patients and in Group B, 52 (72.2\%) patients had pain in abdomen. Vomiting was present in $78 \%$ and $75 \%$ cases of group $\mathrm{A}$ and $\mathrm{B}$ respectively.

07 (50\%) patients of group A and 26 (36.11\%) patients of group B consumed smoked and salted fish. Similarly 06 (42.86\%) group A and 41 (56.94\%) group B cases were smoker.

\section{Table-II}

Clinical Examination findings of two groups of patients $(n=86)$

\begin{tabular}{cc} 
Group A* $^{*}$ & Group B * \\
$(\mathrm{n}=14)$ & $(\mathrm{n}=72)$ \\
\hline
\end{tabular}

General Examination Findings

\begin{tabular}{lcc} 
Anemia & $09(64.28)$ & $67(93.06)$ \\
Jaundice & $01(7.14)$ & $02(02.78)$ \\
Dehydration & $05(45.71)$ & $08(11.11)$ \\
Supraclavicular LN & $01(7.14)$ & $02(02.78)$ \\
Loco-regional Examination Findigns & \\
Lump & $07(50)$ & $43(59.72)$ \\
Ascites & $02(14.28)$ & $13(18.06)$ \\
Liver & 00 & $04(5.56)$ \\
\hline
\end{tabular}

- Figures in parentheses represent percentages

Table no III shows that 67 (93.06) cases of group B was anaemic. Lump was present in $07(50 \%)$ of group A patients and 43(59.71\%) group B patients, and visible peristalsis $05(35.71 \%)$ and $23(31.94 \%)$ cases respectively.
Ba-meal study was done in all the 86 cases. 06(57.14\%) group A and 34 (66.67\%) group B cases were positive for carcinoma of stomach by Ba-meal examination.

\section{Endoscopic Examination}

On endoscopy 92.86\% of group A and 95.83\% of group B patients had lesions suggestive of gastric carcinoma. Tissue biopsy was taken from all the cases. Poorly differentiated carcinoma stomach was found in $35.71 \%$ of group A and $41.14 \%$ of group B patients. The histopathological findings were inconclusive only in 1 patient of group A and 16 (22.86) cases of group B patients.

\section{Surgical management}

Exploration was done in 61 out of 86 patients of carcinoma of the stomach. Palliative procedure was possible on $78.57 \%$ of group A patients $69.44 \%$ in group $\mathrm{B}$ patients.

In both the groups' maximum number of tumour was in the antrum. The growth was present in the antrum in $63.6 \%$ of cases in group A and $78 \%$ in group B. $36.4 \%$ patients of Group A and 14\% patrients of Group B patients had growth in body of the stomach. Growth in cardia (8\%) was found only in elderly (group B) patients.

Tumor status as observed during exploration, was recorded according to TNM classification. $\mathrm{T}_{3}$ stage was present in 05 of 11 in group A (45.45\%) and 13 of 50 ( $26 \%$ ) of cases present in elderly ( group B ) patients. $\mathrm{T}_{4}$ status was present in 06 of group A (54.55\%) and 28 (56\%) of 50 cases of group B. Findings were significant ( $p$ value $<0.05$ ). This comparison is shown in Table IV.

\section{Table-III}

\begin{tabular}{|c|c|c|c|}
\hline \multicolumn{4}{|c|}{ Endoscopic Biopsy Results of two groups of patients } \\
\hline & & Group A (\%)N=14 & Group B (\%)N=70 \\
\hline \multirow[t]{5}{*}{ EndoscopicBiopsy Report } & Well differentiated & $04(28.57)$ & $06(08.57)$ \\
\hline & Moderately differentiated & 02(14.29) & $14(20)$ \\
\hline & Poorly differentiated & $05(35.71)$ & 33(41.14) \\
\hline & Diffuse & 02(14.29) & 01(01.430) \\
\hline & Inconclusive & $01(07.14)$ & $16(22.86)$ \\
\hline \multirow[t]{3}{*}{ USG } & Liver metastasis & 0 & 4 \\
\hline & Ascitis & 4 & 15 \\
\hline & Lymphadenopathy & 6 & 37 \\
\hline Ba meal & Suggestive & $6(33 \%)$ & $34(66.6 \%)$ \\
\hline
\end{tabular}

- Figures in parentheses represent percentages 
Table- IV

\begin{tabular}{|c|c|c|}
\hline Tumor status * & Group A (\%) & Group B (\%) \\
\hline $\mathrm{T}_{2}$ & 00 & 09(18) \\
\hline $\mathrm{T}_{3}$ & $05(45.45)$ & $13(26)$ \\
\hline $\mathrm{T}_{4}$ & 06(54.55) & $28(56)$ \\
\hline & 11 & 50 \\
\hline
\end{tabular}

*Note - there was no patients with T1 tumor

- Figures in parentheses represent percentages

Lymph node involvement was present in 09(81.82\%) of Group A and 46(92\%) of Group B cases. Peritoneal involvement was present in 01 (09.09\%) and 09 (18\%) cases of Group A and Group B respectively. Hepatic involvement was found in 02(18.18\%) and 09(18\%) of cases of Group A and Group B respectively. Nodal involvement of these patients with carcinoma of the stomach has been presented and compared in table V.

Table-V

Showing difference in Nodal Involvement ( as per TNM classification ) in two groups of gastric cancer patients

\begin{tabular}{lcc} 
Lymph node status & Group A (\%) & Group B (\%) \\
\hline $\mathbf{N}_{0}$ & $02(18.18)$ & $03(8)$ \\
$\mathbf{N}_{1}$ & $03(27.27)$ & $18(30)$ \\
$\mathbf{N}_{2}$ & $06(45.45)$ & $28(26)$ \\
$\mathbf{N}_{X}$ & 00 & $01(06)$ \\
\hline Total & 11 & 50 \\
\hline
\end{tabular}

As the patients presented with incurable tumor mass exploration was done with palliative intent. Resection was possible in 10 (90.91\%) young patients ( group A) and 29 (58\%) elderly patients ( group B )..Procedures performed has been tabulated in table VI. 72.7\% group A patients were treated by distal partial gastrectomy. Whereas group B patients were treated by distal partial gastrectomy in $46 \%$ and gastrojejunostomy in $42 \%$ cases. $\mathrm{p}$ value $>0.05$.
Table-VI

Extent of Resection in Patients with Ca-stomach

\begin{tabular}{lcc} 
Procedure & Group A (\%) & Group B (\%) \\
\hline Total gastrectomy & $02(18.18)$ & $02(4)$ \\
Proximal partial gastrectomy & 00 & $03(6)$ \\
Distal partial gastrectomy & $08(72.73)$ & $23(46)$ \\
Distal subtotal gastrectomy & 00 & $01(2)$ \\
Gastrojejunostomy & $01(9.09)$ & $21(42)$ \\
\hline Total & 11 & 50 \\
\hline
\end{tabular}

The mortality was 02 (18.18\%) among group A and in 05 (10\%) in group B. Postoperative complications developed in 16\% patients of group B.

\section{Discussion:}

A total of 86 histopathologically confirmed cases were included in the present study. Among them 14 cases were included in young group of which 11 cases were operated. In elderly group 72 cases were included and 50 cases were operated .In 22 cases of elderly patients operation could not be done either for refusal of operation or extensive disease involvement .

In the present study the incidence of gastric carcinoma in young group was $16 \%$ ( 14 of 86 patients). ,. In one review Milne et al ${ }^{7}$, about $10 \%$ patients were found below 45 years and in another study it was $13 . \%{ }^{4}$ in a series of 130 cases. The patients below 45 yeas has been grouped as early onset gastric carcinoma ( EOGC ). ${ }^{7}$ Though the diagnosis of gastric neoplasm is sometimes reserved in young patients, symptoms observed in this age group did not differ from those in adults (8-11). Similar observations was also noted in this study. A recent study reported observations that early onset gastric carcinoma (EOGC) has molecular genetic profile different from elderly group of patients where environmental factors are held responsible for carcinogenesis. ${ }^{7}$ In another study, a statistically significant increase in number of patients below the age of forty years was seen in cancers involving oesopageo gastric junction in Indian subcontinent. ${ }^{12}$

In the present study the main presenting symptoms were abdominal pain and anorexia in both the groups. Another study from Iran revealed abdominal pain and anorexia to be present in $95 \%$ of cases ${ }^{13}$. Comparable pattern of 
clinical features were reported from India, Pakistan and Nigeria ${ }^{14-17}$

Tobacco smoking has a positive association while increasing consumption of vegetables and dietary products has a protective effect ${ }^{18}$. Smoking was the prominent risk factors in both the groups but smoked and salted fish intake was more in younger group.. In a cohort study, Poulsen (19) and his co workers found association of proton pump inhibitors (PPI ) and H2 receptor blockers with increased incidence of gastric carcinoma. PPI and H2 receptor blockers are available as over the counter drugs and are used randomly and indiscriminately . Effect of these drugs in our population could not be assessed in this study.

Half of the young patients and 43 (59.77\% ) elderly cases had visible or palpable lump. Other studies showed similar observations in different countries(4,14-16). Ascites was present in $14.28 \%$ and $18.06 \%$ cases and hepatomegaly present in $05.56 \%$ cases only.. Similar observation were reported from neighboring countries. (14-16)

Endoscopy is investigation of choice for diagnosis of gastric carcinoma. Numerous reports had demonstrated that its accuracy of diagnosis was greater than $95 \%{ }^{(20)}$. Negative results were more common in younger age group in this series. Spiral CT scan has limited ability to identify lymph node metastases but can detect adjacent organ invasion. Whenever possible these modalities may be used for preoperative assessment. Endoscopic ultrasound has been found $80 \%$ and $68.8 \%$ accurate respectively for Tumor and Nodal status in a study in Korea. (21) Pre operative assessment of nodal status therefore remains difficult and has low specificity but a combined approach might give better understanding and outcome.

Histopathologically in young patient's malignancy were more aggressive than older group. The percentage of diffuse variety was more in young group and poorly differentiated were more in elderly group.

TNM staging was done in all the operated cases. In both the groups malignancy was in advanced state. $T_{3}$ stage tumor was more in young group whereas, $\mathrm{T}_{4}$ was more common in the elderly group and was statistically significant. Involvement of peri gastric and extra gastric lymph nodes are found directly related to tumor size and depth of invasion. In a Japanese study lymph node involvement was $0 \%$ for tumors less than $1 \mathrm{~cm}$, it reached to $46 \%$ for peri gastric and $15 \%$ for extra gastric nodes for a $4 \mathrm{~cm}$ lesion, (22) This also indicates early lymph node metastasis in carcinoma of the stomach. On the other hand a German study found no relationship with the size of lymph node and metastatic infiltration ( 23 ). Data from several large series indicate that $60 \%$ to $90 \%$ of patients had primary tumor presenting with involvement of the serosa or invading adjacent organs (24-25). In a study in India cancers were diagnosed in an advanced stage and $70 \%$ had serosal infiltration ${ }^{1}$.

Early reporting and early diagnosis no doubt will improve results of treatment in any type of cancer. In Japan where gastric cancers are diagnosed at an early stage the results are admirable . Kitano has reported $100 \%$ resectability with $\mathrm{T} 1 \mathrm{~A}$ and $\mathrm{T} 1 \mathrm{~B}$ tumours with 5 year disease free survival of 99.8 for $\mathrm{T} 1 \mathrm{a}$ and $98.7 \%$ for T1B gastric cancers following laparoscopic intervention. ( 26 ) The reason for late presentation are many. One important issue in our patients may be due to vague symptoms and casual use of PPI and H2 receptor blockers as self medication. In an attempt to promote early presentation of cancers specially in disadvantaged communities Lyon and workers had an innovative approach of involving people in the community . This could improve reporting of breast cancer and bowel cancer. ( 27 ) Similar strategy may improve early presentation in gastric cancers as well.

Lymph node involvement was greater in elderly group than young group of patients. The overall lymph node involvement was over $90 \%$. Sunderlands described an $88 \%$ incidence of involvement of nodes with the proximal lesions ( 28 ). This was also observed in this series that lymph node involement in younger patients were more rapid.

Resection was done in more than $90 \%$ young patients and $58 \%$ in older group. Resection was possible in significantly higher proportion of young patients. This may be due to involvement of body and involvement of fewer lymph nodes or due to more operative fitness in young group. Another factor might be less number of patients in this group.

The maximum palliative surgery was distal partial gastrectomy. Gastrojejunostomy done in older group was 21 (42\%) cases. In other series by pass operation was done in $7.23 \%$ and $5 \%$ cases ( 29 ). In the present 
study the mortality rate was $02(18 \%)$ in young patients and $05(10 \%)$ in older patients. However, none of the operative procedure was statistically significant.

\section{Recommendation:}

More focused studies with more cases are required to identify risk factors and surgical outcome in both groups.

\section{Acknowledgement:}

This study was done in as a part of dissertation in partial fulfillment of FCPS part II examination in Surgery in Chittagong Medical College Hospital.

We are indebted to Professor K.Z. Mamun who has given his valuable time in statistical analysis and over all review of the paper .

\section{References:}

1. Pavithran K, Doval DC, Pandey KK. Gastric cancer in India, Epidemiology note, International and Japanese Gastric cancer association. Gastric Cancer. 2002:5; 240-243.

2. Primrose JN. Stomach and Duodenum; Russell RCG, Williams NS, Bulstrode JK. Editors; Bailey and Loves Short Practice of Surgery; Arnold, International Student Edition; $23^{\text {rd }}$ ed. 2000:918-926

3. Dohery GM, Way LW, Stomach and Duodenum Way LW. Dohery GM. Editors. Current Surgical Diagnosis and Treatment; International edition; Gastric Carcinoma: $11^{\text {th }}$ ed. 2003:556-559.

4. Deodhar SD, Mohite JD, Joshi AS, Vora IM. Gastric carcinoma in the young (review of 14 cases). J Postgrad Med. 1990;6:27-30.

5. Alam AMMS, Chowdhury T, Anwar S, Jagirder MSU, Hosen MM. Cancer in Chittagong: A cancer based survey. JCMCTA. 1994;5 (S2): 6-25.

6. Khan FA, Shukla AN. Pathogenesis and treatment of gastric carcinoma. Res Ther. 2006;2:196-199.

7. Milne AN, Sitraz R, Carvalho R, Carnerio F, Offerhaus A, Johan G. Early Onset Gastric cancer: On the road to unraveling gastric carcinogenesis . Current Molecular Medicine 2007 ; 7 ( 1 ) ; 15-28.

8. Bellegie NJ, Dahlin DC. Malignant disease of the stomach in young adults; Ann Surg. 1953;138:7-12.

9. Mc Neer G, Pack GT. In "Neoplasms of the Stomach” London: Pitman Medical Publishing Co. 1967; pp 126.

10. Sharma GC, Vickers P. Gastric carcinoma in the young. Ind J Surg. 1976;38:207-210.

11. Tamura PY, Curtiss C. Carcinoma of the stomach in the young adult. Cancer 1960;13:379-385.

12. Cherian JV, Sivaraman R, Muthusamy AK, Venkataraman J. Stomach carcinoma in the Indian sub-continent : A 16 year trend; Saudi J Gastroenterol 2007; 13 : 114-117.

13. Eskander H, Shostari S, Hossein M, Rahim M, Jalaj H, Meherdad A et al. Clinical profile of gastric cancer in
Khujestan, Southwest of Iran. World J gastroenrol 2006; 12 (4): $189-90$

14. Sambasivaiah K, Ibraullah M, Reddy M K , Reddy P V, Wagholiker JS . Clinical profile of carcinoma stomach at a tertiary care hospital in south india . Trop Gastroenterol 2004; 25: 21-26.

15. Phukan R K, Narain, Zomawia E , Hazarika N C, Mahanta $\mathrm{J}$, Dietary habits and stomach cancer in Mizoram, India . India J Gastorenterol 2006; 41 : 418-24

16. Durrani AA, Yaqoob N, Abbasi S, Siddiq M, Moin S. Pattern of gastro Intestinal malignancies in northern Punjab. Pak J Med Sc 2009; 25 (2 ) 302-307.

17. Bakari AA, Ibrahim A G, Gali BM, Dogo D, Nggada HA. Pattern of Gastric Canaer in Nort -eastern Nigeria : A clinic pathological study. Journal of Chinese Clinical Medicine ; $2010: 5$ (4)

18. Trendaniel J, Boffetta P, Buiatti E, Saracci R, Hirsch A. Tobacco smoking and Gastric Cancer: Review and Meta analysis . Int J Cancer 1997 ; 72 ( 4 ) 565-73.

19. Poulsen A H, Christensen S, McLaughin J K, Thomsen R.W, Sorensen H T, Olsen JH and Friis S. Proton pump inhibitors and risk of gastric cancer: A population based cohort study. Br J Cancer 2009 ;100 (9) : 1503-07

20. Dekher W, Tygat GN. Diagnostic accuracy of Fibre endoscopy in the detection of upper intestional malignancy; a follow up analysis. Gastroenterology. 1997;73:710.

21. Xi W D, Zhao C, Ren G S , Endoscopic Ultrasonography in pre operative staging of gastric cancer : determination of tumor invasion depth, nodal involvement and surgical resectability. World J Gastroenterol 2003; 9(2 ) : 254-257.

22 Yasuda K, Shirishi N, Sumatsu T, Yamaguchi K, Adachi Y, Kitano S. Rate of detection of lymph node metastasis is correlated with the depth of submucosal invasion in early stage gastric carcinoma ; Cancer 1999; 85 : 10; 2119 -23

23. Moing S P, Zirbes T K, Schroder W, Baldus S E, Lindermann DG, Dienes H P, Holscher A H. Staging of gastric cancer : correlation of lymph node size and metastatic infiltration. American Journal of Roentgenology. 1999 ;173 ( 2): 365-367.

24. Serlin O, Keehn R, Higgins G, Harrower HP, Mendeloff G. Factors related to survival follow resection for gastric carcinoma analysis of 903 cases. Cancer. 1977,40:1318.

25. Papaachriston D, Shui M. Management by enbloc multiple organ resection of carcinoma of the stomach invading adjacent organs. Surg Gynaecol Obstret. 1981:46.

26 Kitano S, Shiraishi N, uyama I, Sugihara K, Tanigawa N. A multicenter study on oncologic outcome of laparoscopic gastrectomy for early gastric cancer in Japan. Ann Surg. 2007; 245 ( 1 ): 68-72.

27. Lyon D, Knowels J, Slater B and Kennedy R. Improving the early presentation of cancer symptom in disadvantaged communities : putting local people in control. Br J cancer ; 2009; 101 (52 ): s49-s54.

28. Barr H, Greeall MJ. Carcinoma of the stomach; Morris PJ and Mac RA editor; Oxford Textbook of Surgery; vol.1; Oxford Medical Publication; 931-943.

29. Sayeed A. Management of carcinoma of stomach: problems and Strategies. J Bangladesh College of Physicians and Surgeons. 1999;17 (2) :54-57. 